\title{
Diurnal and semidiurnal tide in the upper middle atmosphere during the first year of simultaneous MF radar observations

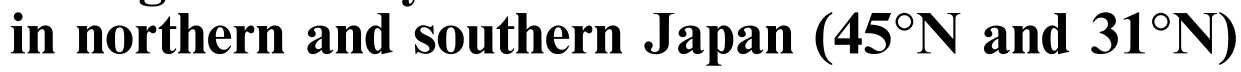

\author{
K. Hocke*, K. Igarashi \\ Communication Research Laboratory, Tokyo, Japan \\ Received: 20 October 1997 / Revised: 10 June 1998 / Accepted: 15 September 1998
}

\begin{abstract}
The climatology of mean wind, diurnal and semidiurnal tide during the first year (1996-1997) of simultaneous wind observations at Wakkanai $\left(45.4^{\circ} \mathrm{N}\right.$, $\left.141.7^{\circ} \mathrm{E}\right)$ and Yamagawa $\left(31.2^{\circ} \mathrm{N}, 130.6^{\circ} \mathrm{E}\right)$ is presented. The locations of the radars allow us to describe the latitudinal dependence of the tides. Tidal amplitude and phase profiles are compared with those of the global scale wave model (GSWM). While the observed amplitude profiles of the diurnal tide agree well with the GSWM values, the observed phase profiles often indicate longer vertical wavelengths than the GSWM phase profiles. In contrast to the GSWM simulation, the observations show a strong bimodal structure of the diurnal tide, with the phase advancing about 6 hours from summer to winter.
\end{abstract}

Key words. Meteorology and atmospheric dynamics (middle atmosphere dynamics; waves and tides)

\section{Introduction}

Tides in the upper middle mesosphere over Japan were mainly observed by the Kyoto meteor radar in the past (e.g. Tsuda et al., 1988; Tsuda et al., 1983; Vincent et al., 1988). The observations of the MF radar at Yamagawa $\left(31^{\circ} \mathrm{N}\right)$ are expected to show quite similar wind measurements and tidal characteristics as those observed at Kyoto which is $4^{\circ}$ further north. A comparison between the Yamagawa MF radar and the MU radar at Shigaraki (near to Kyoto) resulted in a good agreement for the measured winds during the time from 13 to 16 September, 1994 (Igarashi et al., 1996). The MF radar at Wakkanai $\left(45^{\circ} \mathrm{N}\right)$ in northern Japan is separated by $14^{\circ}$ of latitude from the Yamagawa MF radar. According to

Correspondence to: K. Hocke

* Present address: DLR, Kalkhorstweg 53,

17235 Neustrelitz, Germany, E-mail: hocke@nz.dlr.de existing tidal models (e.g., Vial, 1986; Forbes and Hagan, 1988) the observed tidal characteristics at Wakkanai are expected to be significantly different from those observed in Yamagawa. The simultaneous wind observations of the MF radars at Yamagawa and Wakkanai are appropriate to describe the latitudinal dependence of tides in the Asian-Pacific sector at middle latitudes.

\section{Observations and data analysis}

We use data of the MF radars at Yamagawa $\left(31.2^{\circ} \mathrm{N}\right.$, $\left.130.6^{\circ} \mathrm{E}\right)$ in southern Japan and Wakkanai $\left(45.4^{\circ} \mathrm{N}\right.$, $141.7^{\circ} \mathrm{E}$ ) in northern Japan between September 1996 to September 1997. Both radars have an operation frequency of $1.95 \mathrm{MHz}$ and measure winds at heights between 60 and $100 \mathrm{~km}$ with a height resolution of $2 \mathrm{~km}$ and time resolution of $2 \mathrm{~min}$ at Yamagawa and $4 \mathrm{~min}$ at Wakkanai. The wind data are calculated by means of the full correlation analysis (FCA) algorithm of the University of Adelaide (Briggs, 1984). The experimental configurations of the radars were described by Igarashi et al. (1996).

The further data analysis was performed by using hourly averages of the horizontal wind. The observed wind was decomposed in contributions due to a constant, a linear trend, the 2-day wave, diurnal, semidiurnal and terdiurnal tide by using least squares fit and singular value decomposition (SVD) which avoids unrealistic solutions of the equation system (Press et al., 1992). The estimate by the error ellipsoid yields small amplitude and phase errors less than $1 \mathrm{~m} / \mathrm{s}$ and $10^{\circ}$. The data window has a length of 10 days and is shifted with a time step of 5 days. The amplitudes and phases are therefore calculated as function of time which allows the description of the seasonal variations. The amplitudes and phases are only calculated if the data gaps within the window are less than $1 / 3$ of the window length. This is related to the limit chosen by Thayaparan et al. (1995).

The presented tidal amplitudes and phases can be contaminated by tidally modulated gravity wave flux which is not removed by the applied decomposition 
analysis. Instrumental factors must also be considered by the comparison between our MF radar observations, satellite observations and results of tidal models. Burrage et al. (1996) showed that MF radar winds tend to be smaller in magnitude than the HRDI measurements of the UARS satellite.

\section{Results}

\subsection{Mean wind and amplitudes of tides and 2-day wave}

The contours of mean wind and tidal amplitudes at Yamagawa are depicted in Fig. 1 for the time from September 1996 to September 1997. The graphs on the left hand side correspond to the zonal component, and the graphs on the right hand side are due to the meridional component. Contour spacing is $10 \mathrm{~m} / \mathrm{s}$ for the zonal mean wind and else $5 \mathrm{~m} / \mathrm{s}$. At the bottom of each graph the cross section of the contours at height $86 \mathrm{~km}$ is shown which can help to understand and compare the contours. The scale for the cross section is on the right hand axis of the graphs. As mentioned before the mean wind and the tidal amplitudes are calculated with a sliding window of 10 days length. Long-term variations due to planetary waves, intraseasonal waves or to the seasons are obviously present in the contours and cross sections.

Features of the contours at Yamagawa are:

1. Sudden onset of the eastward winter jet at the end of December 1996 (as seen in the graph of the mean eastward wind).

2. Enhancement of the meridional component of the 2-day wave at the end of July, this is in agreement with other observations which indicate that the 2-day wave is a phenomenon of the summer hemisphere (Harris, 1994; Jacobi et al., 1997).

3. Strong diurnal tide with amplitudes of $20-40 \mathrm{~m} / \mathrm{s}$, amplitude enhancements in December/January, March/April, July and September, zonal diurnal winds are greater in winter than in summer.

4. Semidiurnal tide in the range of $10-20 \mathrm{~m} / \mathrm{s}$, small seasonal variability of the semidiurnal tide.

The long-term MF radar observations at Adelaide $\left(35^{\circ} \mathrm{S}, 138^{\circ} \mathrm{E}\right)$ show a quite different amplitude variation of the diurnal tide (Vincent et al., 1998). The amplitudes of both wind components at Adelaide have strong maxima of $25 \mathrm{~m} / \mathrm{s}$ around March and secondary maxima in July/August and October. A similar amplitude variation is presented by Vincent et al. (1998) for the diurnal tide at Kauai $\left(22^{\circ} \mathrm{N}, 160^{\circ} \mathrm{W}\right)$ in the Northern Hemisphere. Contrary to the observations at Adelaide and Kauai, the Yamagawa observations show a strong maximum of the diurnal tide in December/January. Moreover the diurnal tide at Yamagawa is stronger than at Adelaide and Kauai. The amplitudes of the semidiurnal tide at Adelaide, Kauai and Yamagawa are quite similar.

The contours at Wakkanai are depicted in Fig. 2. The contour spacing is the same as in Fig. 1. There are three major data gaps where the operation of the radar failed. The sudden onset of the eastward winter jet was also observed at Wakkanai over the time from 24-31 December 1996 when the radar was operated. Because of our data rejection criterium, the length of the data window, the time step of the sliding window and radar off-time before and later than 24-31 December 1996 the onset of the winter jet is not documentated in the contours but it will be shown elsewhere.

Features of the contours at Wakkanai are:

1. Strong zonal wind shear from westward wind of about $30 \mathrm{~m} / \mathrm{s}$ (dashed contours below $82 \mathrm{~km}$ height) to eastward wind of $30 \mathrm{~m} / \mathrm{s}$ (solid contours above $82 \mathrm{~km}$ height) during summer.

2. Associated with this wind shear, the diurnal tide is strong below $82 \mathrm{~km}$ during summer and decreases rapidly with increasing height, in particular the zonal component.

3 . The enhancement of the meridional component of the 2-day wave is seen in end of July, this is simultaneous with Yamagawa (Fig. 1).

4. Diurnal and semidiurnal tide are comparable, except for the periods January-March and August/September where the semidiurnal tide is greater (amplitudes about $20 \mathrm{~m} / \mathrm{s}$ ).

\subsection{Seasonal variations of tidal phases}

The phases of the diurnal and semidiurnal tide are depicted in Fig. 3 for Yamagawa and Fig. 4 for Wakkanai as function of month and separately for the heights $82,86,90$ and $94 \mathrm{~km}$. The local time of maximum of the eastward tidal component is indicated by the solid circles while the open circles denote the northward component (the same is true for all following figures).

In particular at Yamagawa a clear bimodal phase structure is seen for the diurnal and semidiurnal tide with fast phase transitions around equinoxes (March, September). From May to August the phase has a welldefined mean value. From October to February the phase of the diurnal tide is earlier than in summer: at height $90 \mathrm{~km}$ the phase of the eastward diurnal component is around $7 \mathrm{LT}$ in winter and around $13 \mathrm{LT}$ in summer. The phases agree roughly with observational studies in Australia, USA, Canada and Kyoto (during winter the phases of our study are around $3-5 \mathrm{~h}$ earlier compared to them). The bimodal structure of the diurnal tide at Yamagawa and Wakkanai is much clearer than those presented in other studies (e.g. Thayaparan et al., 1995; Vincent et al., 1998). Further collection of data over the next few years will show the significance of this feature.

Fig. 1. Contours of mean wind and amplitudes of 2-day wave, diurnal and semidiurnal tide at Yamagawa $\left(31^{\circ} \mathrm{N}\right)$ during the time from September 1996 to September 1997 (derived with a sliding data window of 10 days). The contour spacing is $10 \mathrm{~m} / \mathrm{s}$ for the zonal mean wind and else $5 \mathrm{~m} / \mathrm{s}$. Dashed contours denote negative values (westward or southward mean wind). At the bottom of each graph the cross section of the contours at height $86 \mathrm{~km}$ is depicted. The scale for the cross section is on the right axis of the graph 

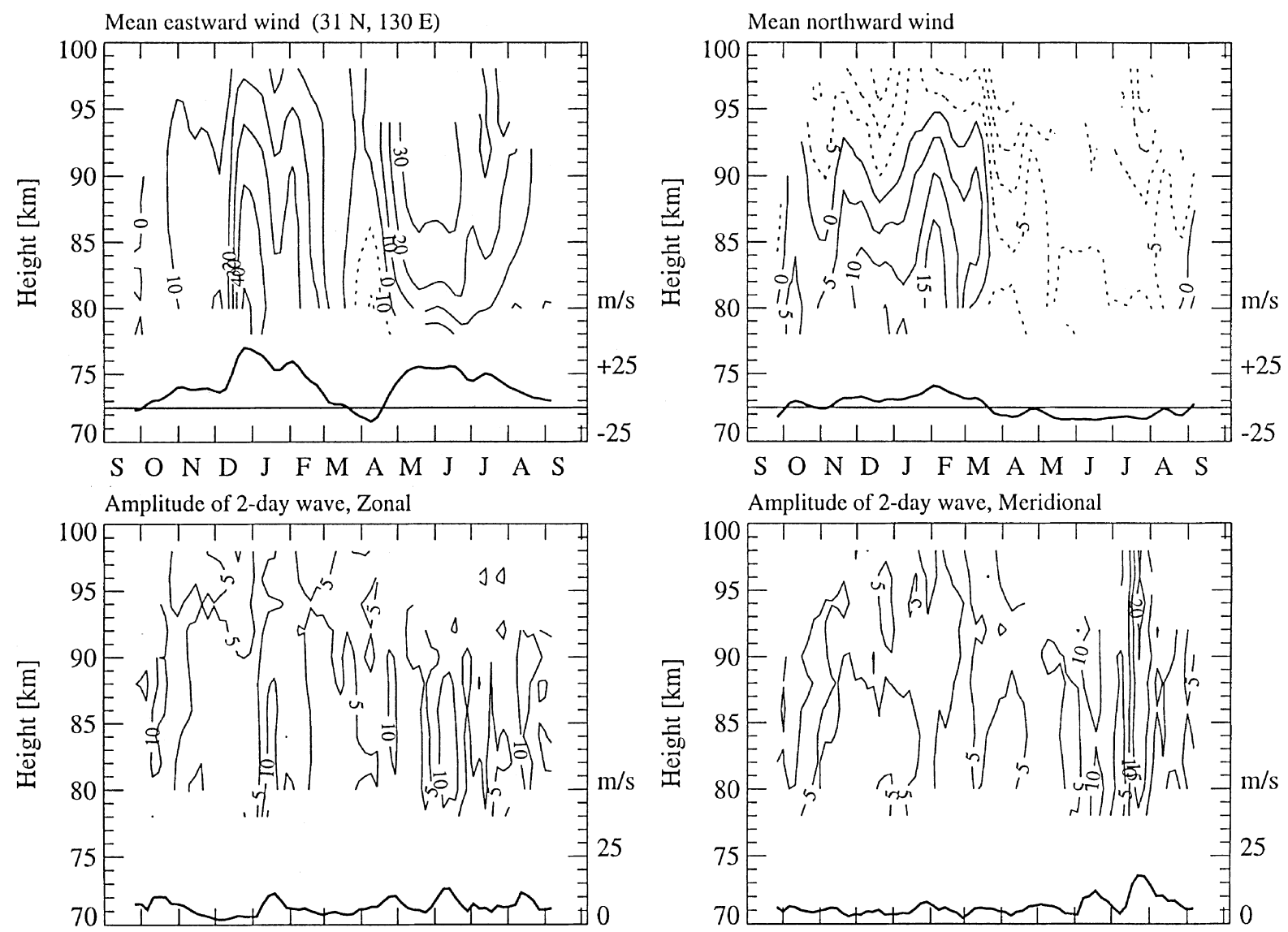

$\begin{array}{llllllllllllll}S & \mathrm{O} & \mathrm{N} & \mathrm{D} & \mathrm{J} & \mathrm{F} & \mathrm{M} & \mathrm{A} & \mathrm{M} & \mathrm{J} & \mathrm{J} & \mathrm{A} & \mathrm{S}\end{array}$

$\begin{array}{llllllllllllll}S & O & N & D & J & F & M & A & M & J & J & A & S\end{array}$
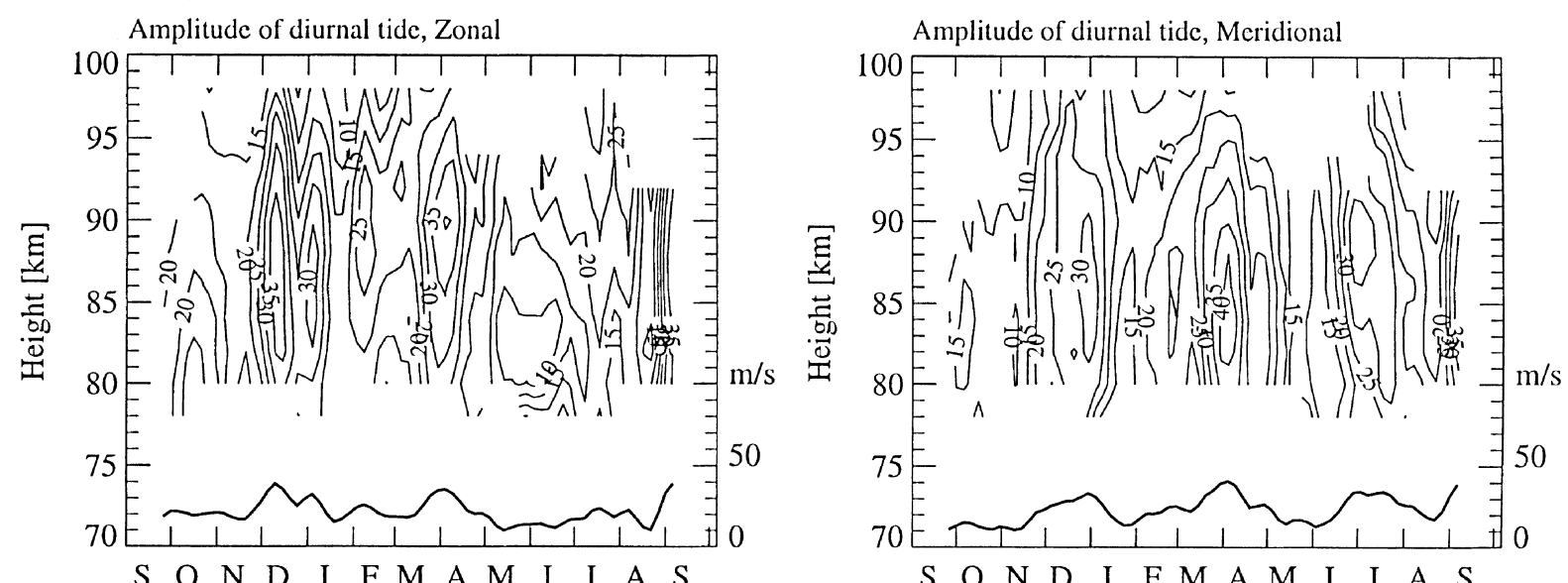

$\begin{array}{lllllllllllll}S & \mathrm{O} & \mathrm{N} & \mathrm{D} & \mathrm{J} & \mathrm{F} & \mathrm{M} & \mathrm{A} & \mathrm{M} & \mathrm{J} & \mathrm{J} & \mathrm{A} & \mathrm{S}\end{array}$

$\begin{array}{lllllllllllll}S & O & N & D & J & F & M & A & M & J & J & A & S\end{array}$

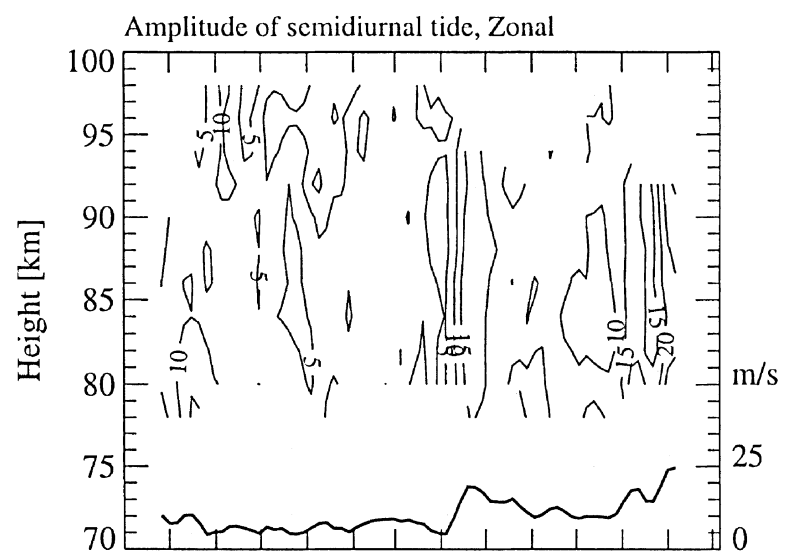

$\begin{array}{lllllllllllll}S & O & N & D & J & F & M & A & M & J & J & A & S\end{array}$

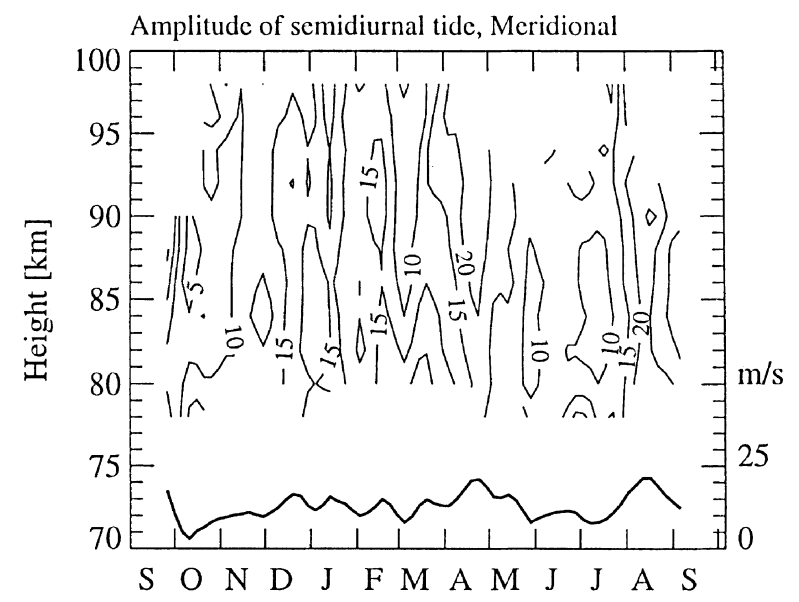


Spectral analysis showed that the quasi-periodic variations of the phase of the diurnal tide are about 17, 22 and in particular 35 days. The strong phase variation of the diurnal tide in June and July at Yamagawa is also seen in the diurnal phase observed at Wakkanai. Possible explanations for these variations could be interaction of the tide with planetary waves or quasi-periodic gravity wave activity. The phases of the diurnal tide at Yamagawa and Wakkanai show almost the same seasonal behaviour and the same absolute values while the corresponding contour plots of the amplitudes are very different. The diurnal tide shows an phase advance of the northward component of around $6 \mathrm{~h}$ against the eastward component at height $82 \mathrm{~km}$ (the phase advance is decreasing with increase of height). The phase advance of $6 \mathrm{~h}$ corresponds to a circular polarisation of the diurnal tide which is predicted by the 'classical' theory (Chapman and Lindzen, 1970).

In contrast to the diurnal tide, the phases of the semidiurnal tide have significant differences at Yamagawa and Wakkanai. In particular from February to April the semidiurnal tide at Yamagawa is in antiphase with the tide at Wakkanai. In June and July there is a phase difference of $2 \mathrm{~h}$ between Wakkanai and Yamagawa. In August and September the phases are the same at Wakkanai and Yamagawa. It will be of interest if this behaviour is also observed in the next few years. The antiphase relationship during February - April could indicate the generation of semidiurnal tidal modes $(2, n)$ with high meridional indices $\mathrm{n}$ by mode coupling in the mesosphere (probably $n=6$ according to Fig. 7 in Forbes, 1995 or Fig. 1 in Forbes, 1982). The high meridional index is necessary for a node in the horizontal velocity expansion function between Yamagawa and Wakkanai $\left(31^{\circ}\right.$ and $\left.45^{\circ} \mathrm{N}\right)$. The phase height profiles of April which will be shown later show an upward propagating tide of a wavelength less than $40 \mathrm{~km}$ and do not contradict a main contribution of the $(2,6)$ mode.

Compared to the long-term observations of the semidiurnal tide at Collm $\left(52^{\circ} \mathrm{N}, 15^{\circ} \mathrm{E}\right)$ by Schminder et al. (1997), the bimodal structure of the semidiurnal tide is not so clear at Wakkanai. There are phase transitions in April and September at Wakkanai, but the phase during summer is not constant as in the observations at Collm where the zonal phase is around 7-9 LT from April to September. From July to September there is a linear decrease of the phase at Wakkanai from 10 to $6 \mathrm{LT}$ for the zonal component. The phase values in winter are around $1 \mathrm{~h}$ later than in summer. The seasonal behaviour is in agreement with observations of the semidiurnal phases at London, Saskatoon, Durham and Urbana (Thayaparan et al., 1995).

The phase of the eastward component of the semidiurnal tide at Yamagawa is around 2 LT in winter and around $7 \mathrm{LT}$ in summer. Fast phase transitions are in March/April and September/October. The northward component is leading the eastward component with a phase advance of around 3 hours from April to August. During winter, the phases of both components are closer together. The annual cycle of the phase of the semidiurnal tide at Yamagawa agrees well with the observations at Kauai $\left(22^{\circ} \mathrm{N}, 160^{\circ} \mathrm{W}\right)$ and Adelaide (Vincent et al., 1998).

\subsection{Comparison between the observations and the GSWM model}

The amplitude and phase profile height profiles at Yamagawa and Wakkanai are compared with those of the global scale wave model (GSWM) of Hagan et al. (1995) which follows the succession of earlier tidal models (Vial, 1986; Forbes and Hagan, 1988; Vial and Forbes, 1989). The tidal amplitudes and phases were calculated by this steady-state two-dimensional linearised model for the 15th day of January, April, July and October of 1995 as function of latitude and are longitudinal averages. The data are provided by M.E. Hagan on the CEDAR Data Base in Boulder/Colorado. Since we have only observations over one year and since there is significant tidal variability at Yamagawa and Wakkanai (as discussed in the previous sections), the comparison will be restricted to the main features. Another possible reason for differences between the observations and the tidal simulations of the GSWM might be the prevailing wind fields. A comparison between the observed wind field over Japan and the wind field predicted by the HWM93 model (Hedin et al., 1996) showed that the observed meridional winds over Japan are often around $10-15 \mathrm{~m} / \mathrm{s}$ while the model winds were less than $4 \mathrm{~m} / \mathrm{s}$ at heights $78-98 \mathrm{~km}$ (Hocke and Igarashi, 1998). For the zonal winds, the observations agreed well with the HWM93 values.

The GSWM data at the latitudes of Yamagawa and Wakkanai are compared with the monthly means of the tides observed at Yamagawa and Wakkanai (October 1996, January 1997, April 1997, July 1997). The monthly means were derived as vector average for the phase and as arithmetic average for the amplitude. The plots are depicted for the diurnal tide at Yamagawa and Wakkanai in Figs. 5 and 6, respectively. The results of the semidiurnal tide at Yamagawa and Wakkanai are in Figs. 7 and 8. The meridional tidal component of the model data is indicated by the dash-dotted line, and the zonal component by the solid line (height step of the model data is $4 \mathrm{~km}$ ). The observed meridional component is indicated by open circles and the zonal component by the solid circles.

In the case of the diurnal tide we have a good or very good agreement of amplitudes and phases in April and July for Wakkanai and for Yamagawa. That means, the profiles of the model are almost within the error bars (dotted horizontal lines) of the observed profiles. The error bars show the variability of the observed tides within the month. The error bars of the phase are sometimes very large, when the tidal amplitude goes to zero. The phase depends then on the random data noise.

Fig. 2. Same as Fig. 1 but at Wakkanai $\left(45^{\circ} \mathrm{N}\right)$. The contour spacing is $10 \mathrm{~m} / \mathrm{s}$ for the zonal mean wind and elsewhere $5 \mathrm{~m} / \mathrm{s}$ 

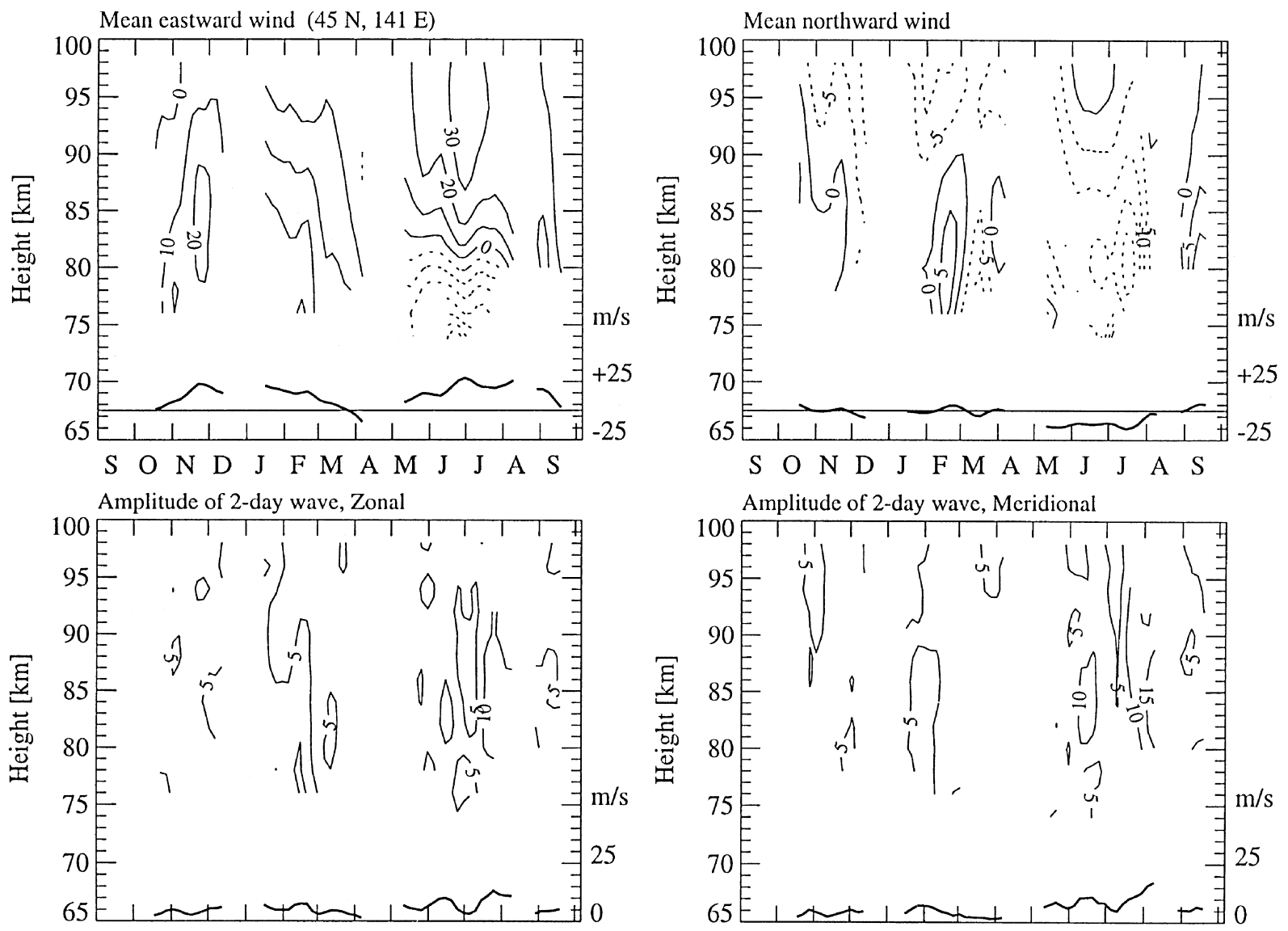

$\begin{array}{lllllllllllll}S & O & N & D & J & F & M & A & M & J & J & A & S\end{array}$

$\begin{array}{llllllllllllll}S & O & N & D & J & F & M & A & M & J & J & A & S\end{array}$

Amplitude of diurnal tide, Zonal

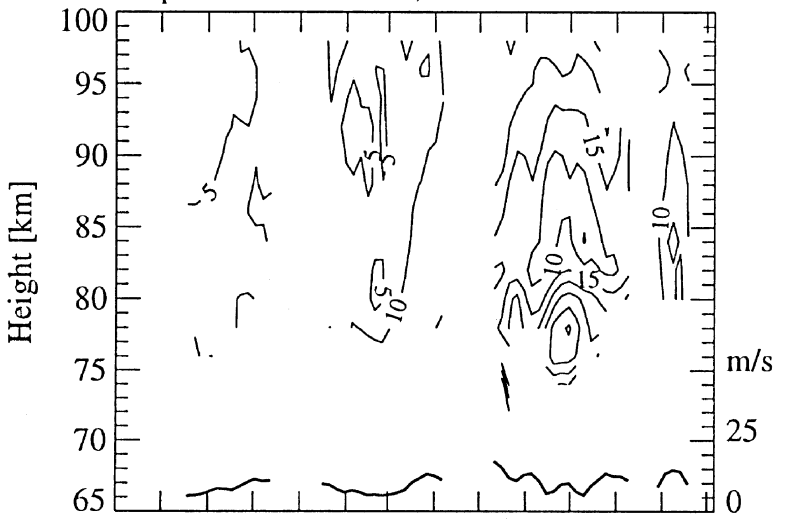

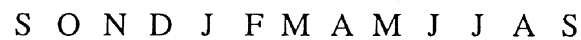

Amplitude of semidiurnal tide, Zonal
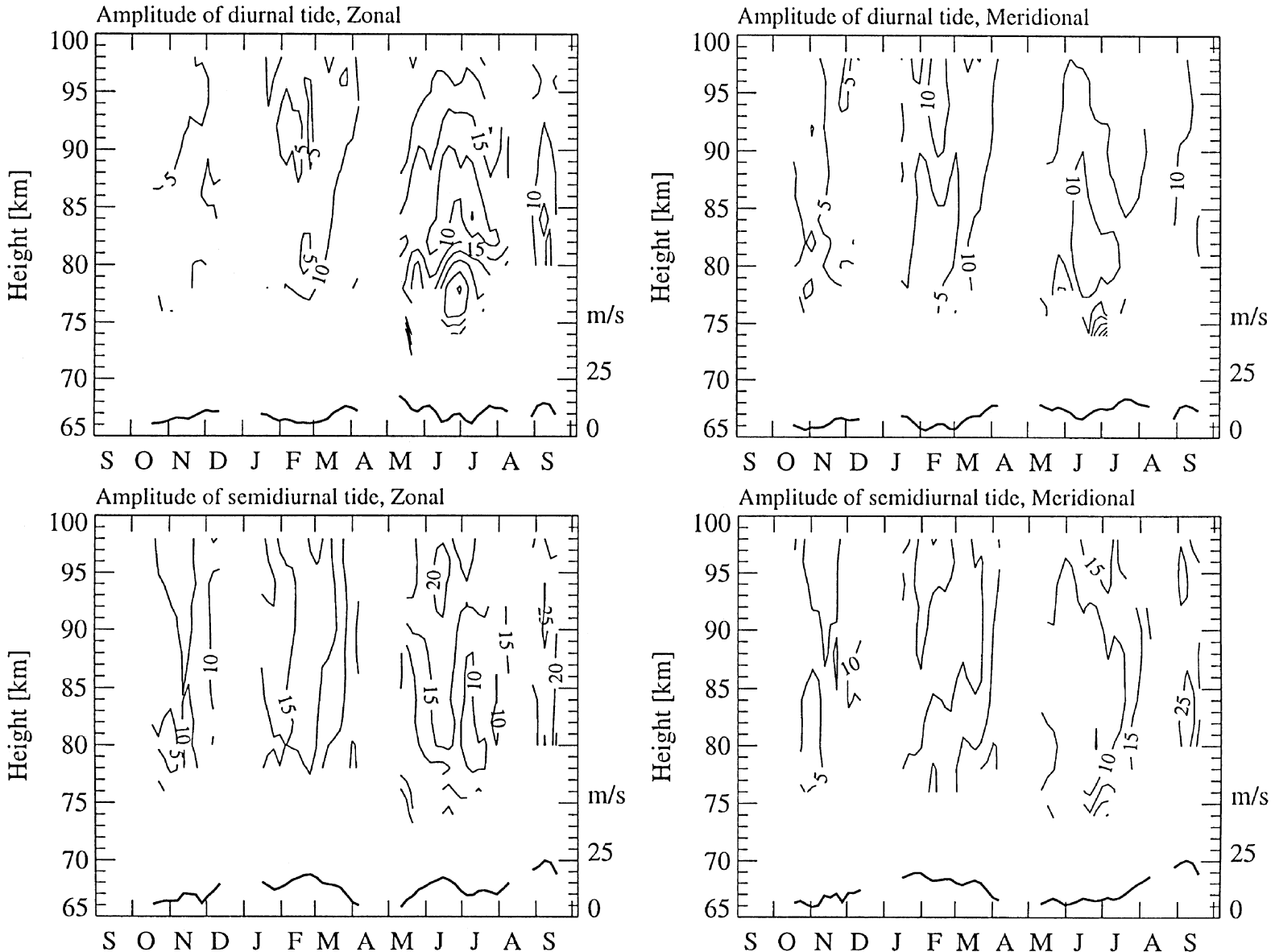

$\begin{array}{llllllllllllll}S & O & N & D & J & F & M & A & M & J & J & A & S\end{array}$

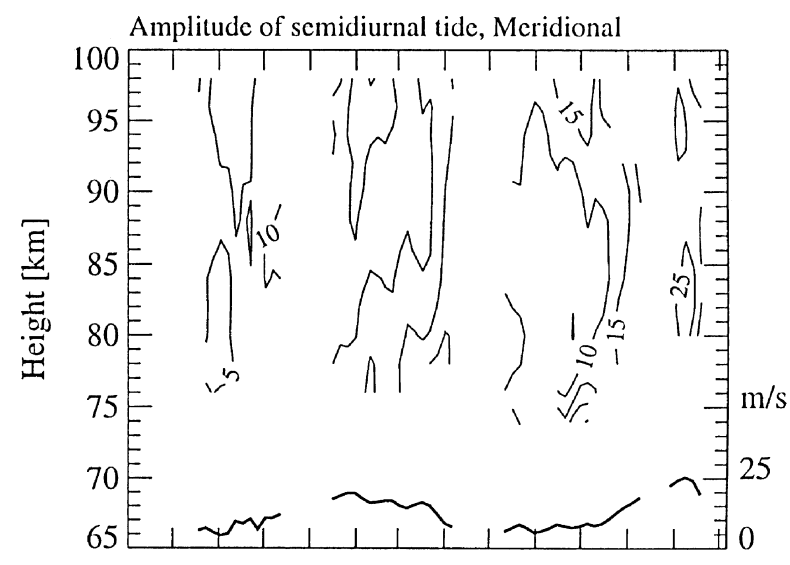

$\begin{array}{lllllllllllll}S & O & N & D & J & F & M & A & M & J & J & A & S\end{array}$ 
The phase of the model tides do not agree with the observed phases in October and January. This is not due to the variability of the observed phases which have well-defined mean values during the winter (OctoberFebruary, Figs. 3 and 4) which do not agree with the model values. Additionally, the short wavelength of the diurnal model tide during fall and winter is not observed (at least in the case of the zonal tidal component). Regarding the phase profiles of the diurnal tide from October (top) to July (bottom of Fig. 3) we see that the observed phase profiles have a strong annual variation (bimodal structure) while the GSWM phase profiles have a comparable small annual variation $( \pm 2 \mathrm{~h}$ ). For April and July the agreement between the GSWM phase profiles and the observations is obviously better than for October and January.

The model data of the semidiurnal tide agree well with the observations in July and October for Wakkanai and Yamagawa, and also well in January for Wakkanai. In April the agreement between observed and modeled
Diurnal tide
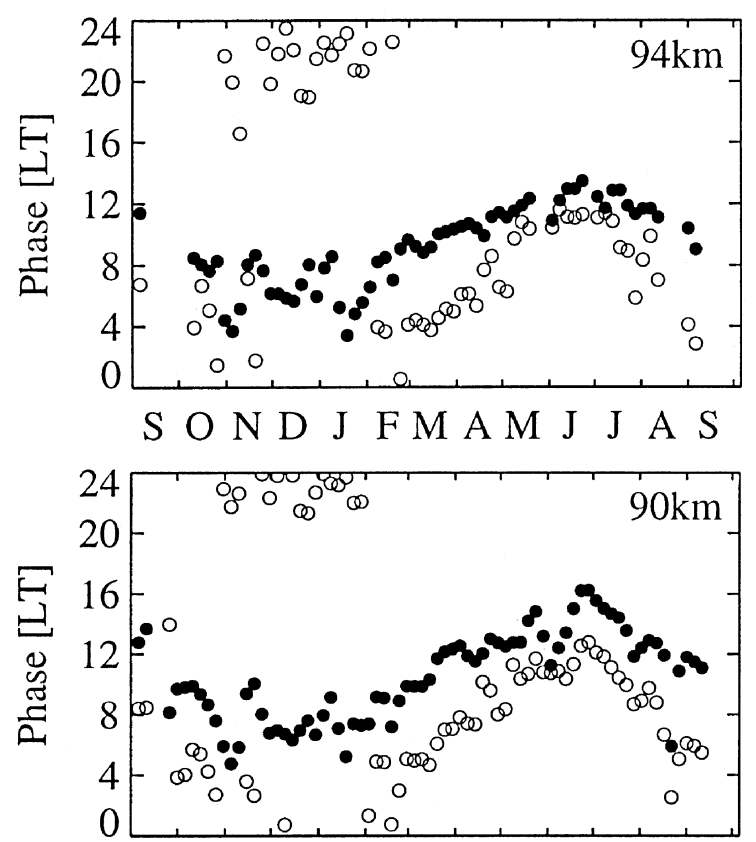

S O N D J F M A M J J A S

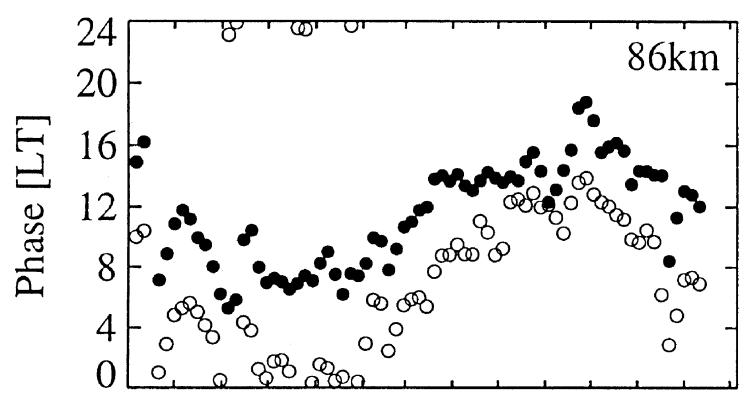

S O N D J F M A M J J A S

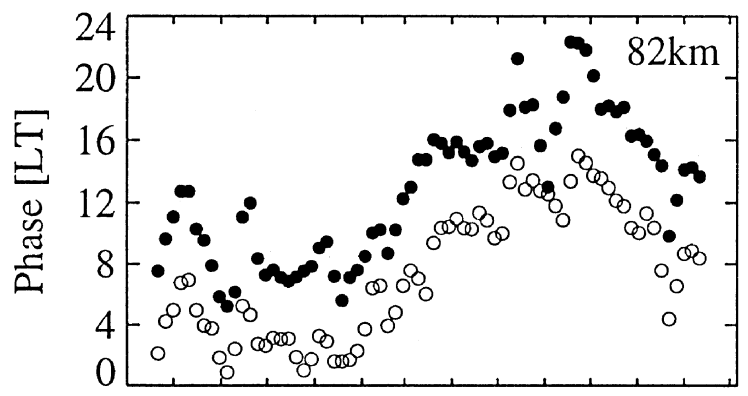

S O N D J F M A M J J A S
Semidiurnal tide $(31 \mathrm{~N}, 130 \mathrm{E})$
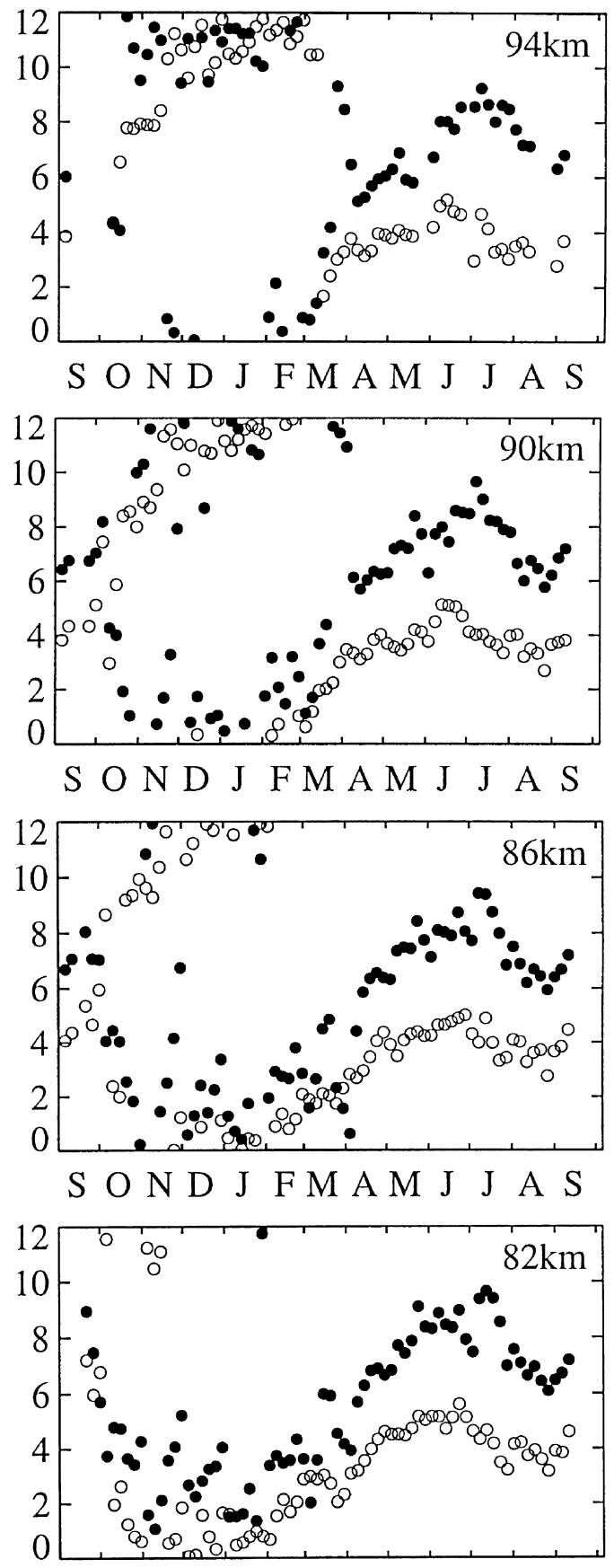

S O N D J F M A M J J A S

Fig. 3. Seasonal variations of the phases of the diurnal (left) and semidiurnal tide (right) at Yamagawa ( $\left.31^{\circ} \mathrm{N}\right)$ for the heights $82,86,90$, and $94 \mathrm{~km}$. The solid circles denote the maximum of local time of the eastward component while the open circles are due to the northward component 
Diurnal tide

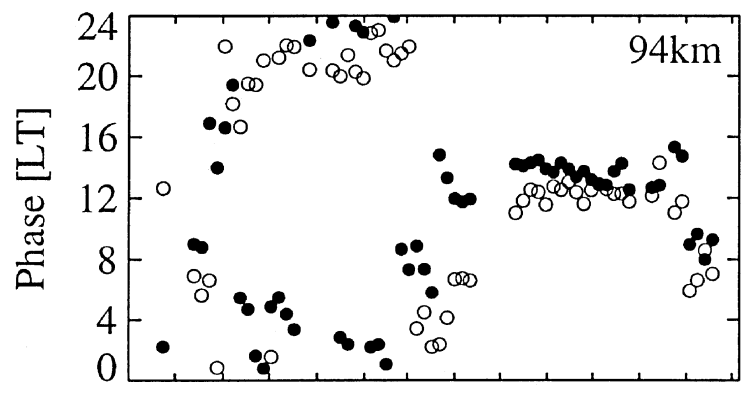

S O N D J F M A M J A S

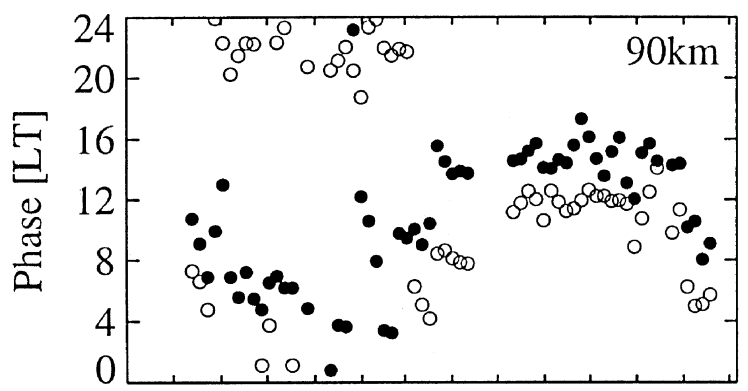

S O N D J F M A J J A S
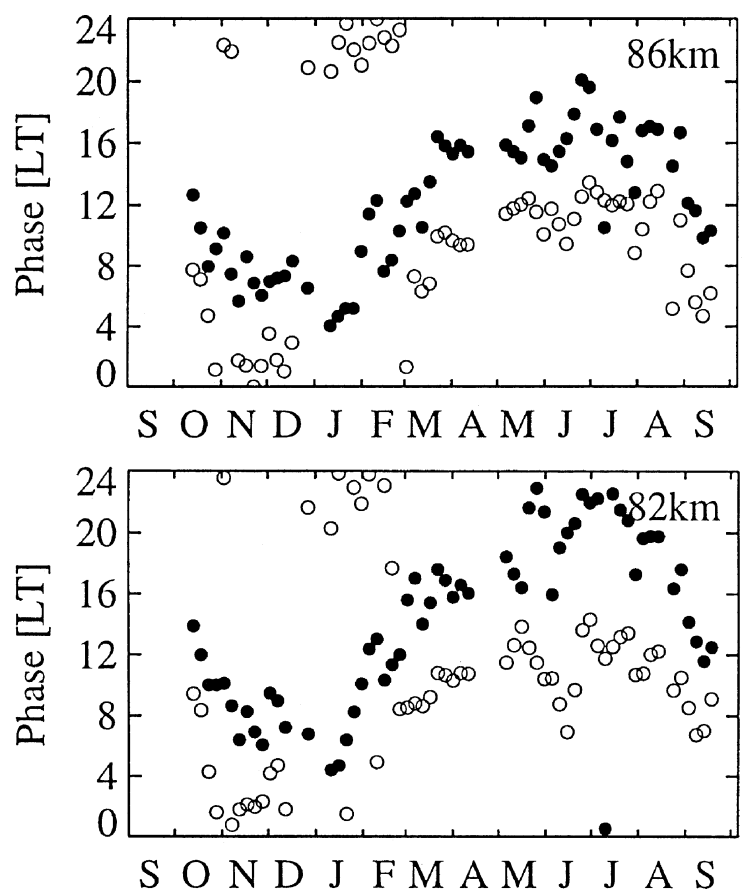

Semidiurnal tide $(45 \mathrm{~N}, 141 \mathrm{E})$

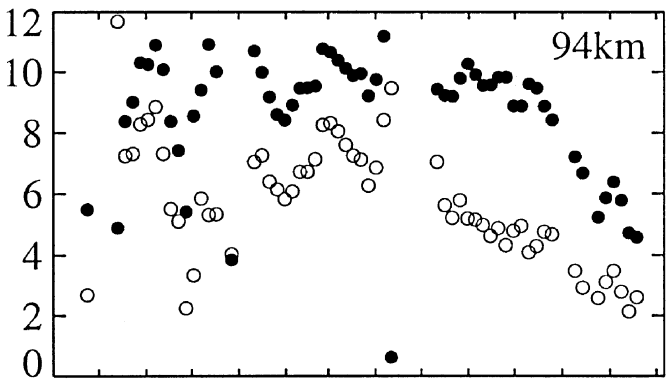

S O N D J F M A M J J A S

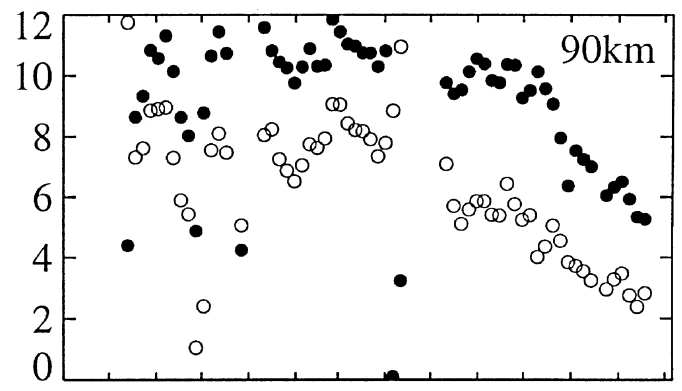

S O N D J F M A M J J A S
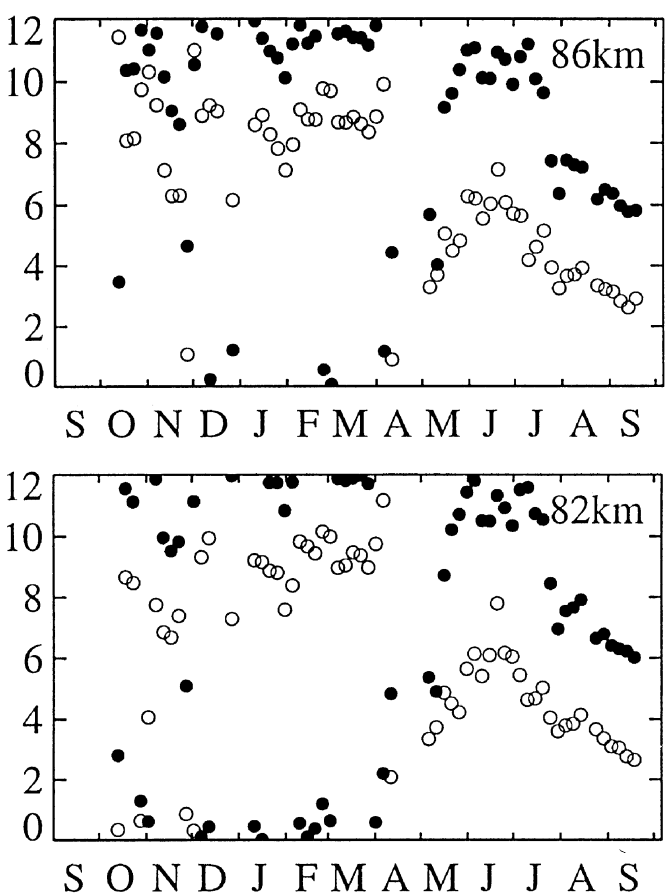

Fig. 4. Same as Fig. 3 but at Wakkanai $\left(45^{\circ} \mathrm{N}\right)$

semidiurnal tide is poor for Yamagawa and Wakkanai. Please note the antiphase relationship between the observed semidiurnal tide at Wakkanai and Yamagawa in April for both velocity components and at all heights, which was discussed in the previous section. The amplitude values of the semidiurnal tide at Wakkanai agree well with those at Collm $\left(52^{\circ} \mathrm{N}, 15^{\circ} \mathrm{E}\right)$ observed by Schminder et al. (1997). The vertical wavelengths are also similar to those at Collm $(50 \mathrm{~km}$ during winter, and $100 \mathrm{~km}$ and more during summer). The absolute phase values of Wakkanai and Collm agree well for January and July.

Vincent et al. (1998) achieved an obvious better agreement between their long-term observations at Adelaide, Christmas Island, and Kauai and the GSWM simulations of the diurnal tide. Compared to our phase profiles of the diurnal tide, their phase profiles have smaller vertical wavelengths and agree better with the GSWM results (except for January at Adelaide where the observed phase profile is quite evanescent). Addi- 
Diurnal tide $(31 \mathrm{~N}, 130 \mathrm{E})$
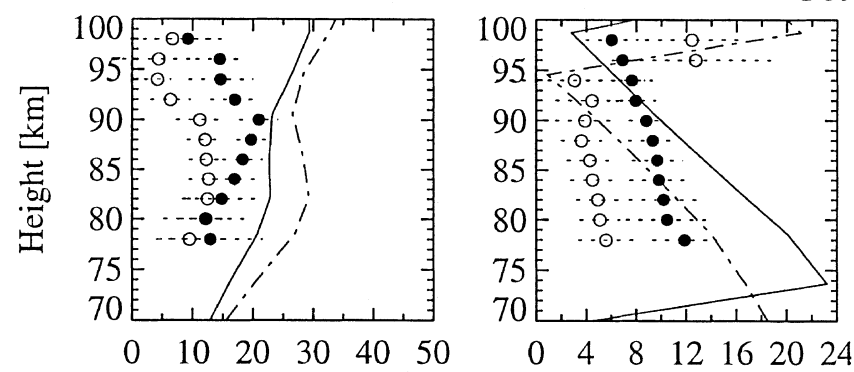

Jan
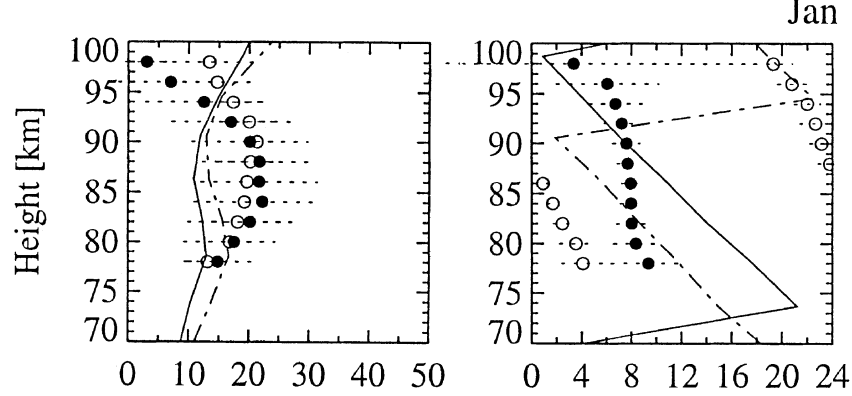

$\mathrm{Apr}$
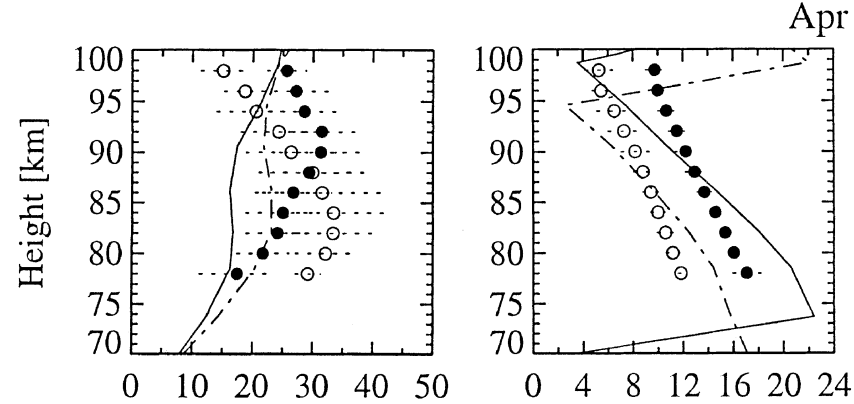

Jul
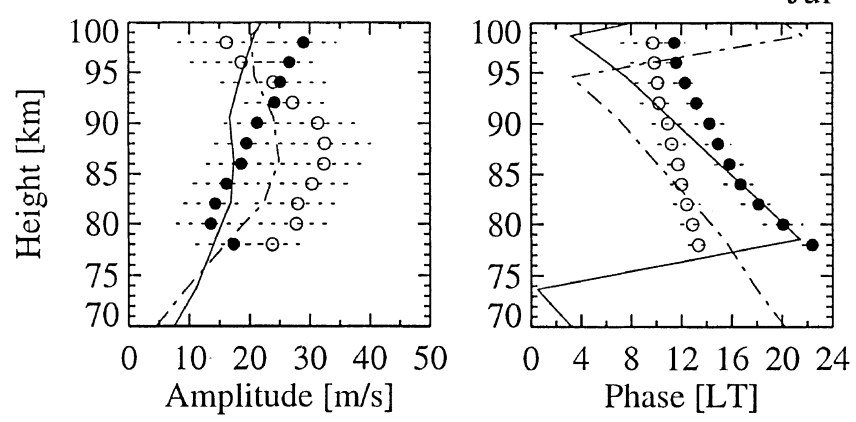

Fig. 5. Monthly means of amplitude and phase profiles of the diurnal tide at Yamagawa $\left(31^{\circ} \mathrm{N}\right)$. Solid circles are due to the observed eastward component, open circles indicate the northward component. The dotted horizontal lines are the error bars due to the variability of the tides within the month. The tidal profiles of the global scale wave model (GSWM) by Hagan et al. (1995) are drawn as a solid line for the eastward component and as a dash-dotted line for the northward component (height resolution is $4 \mathrm{~km}$ )

tionally, the annual variation of the phase profiles of the diurnal tide at Adelaide and Kauai is weaker than at Yamagawa and Wakkanai. The phase behaviour of the semidiurnal tide observed by Vincent et al. (1998) agrees less well with GSWM (comparable to the deviations of our observations from GSWM).
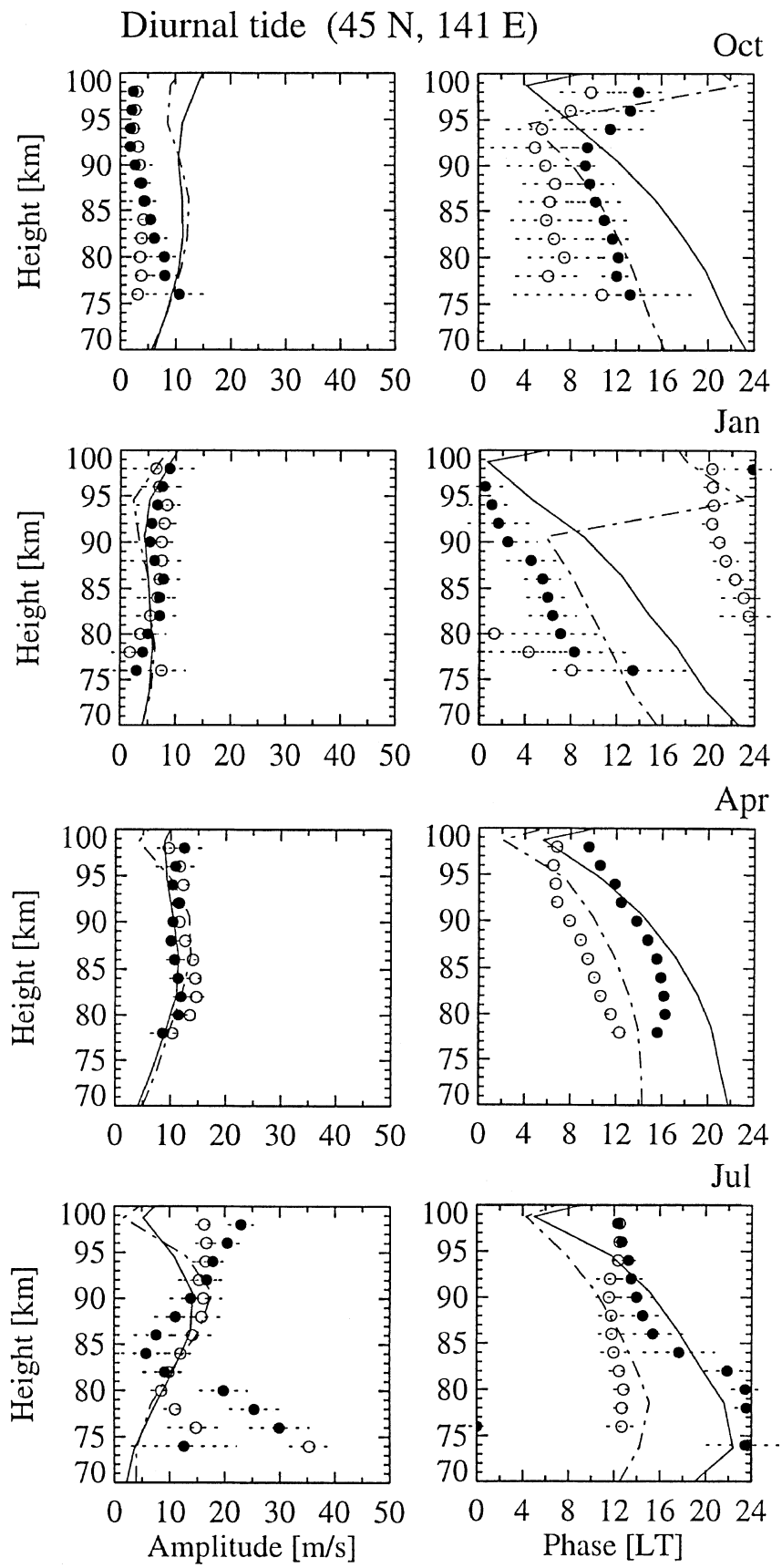

Fig. 6. Same as Fig. 5 but for the diurnal tide at Wakkanai $\left(45^{\circ} \mathrm{N}\right)$

\section{Concluding remarks}

The mean wind and tidal data of the first year of simultaneous MF radar observations in northern and southern Japan were presented. Interesting features are the bimodal structure of the diurnal tide which is not observed so clearly at other radar sites (to our knowledge). The phase of the diurnal tide shows quasiperiodic fluctuations, in particular of a 35-day period. This fluctuation is seen at Yamagawa and Wakkanai and can be due to interaction of the diurnal tide with a planetary wave of this period. The comparison of the tidal observations with the global scale wave model of 

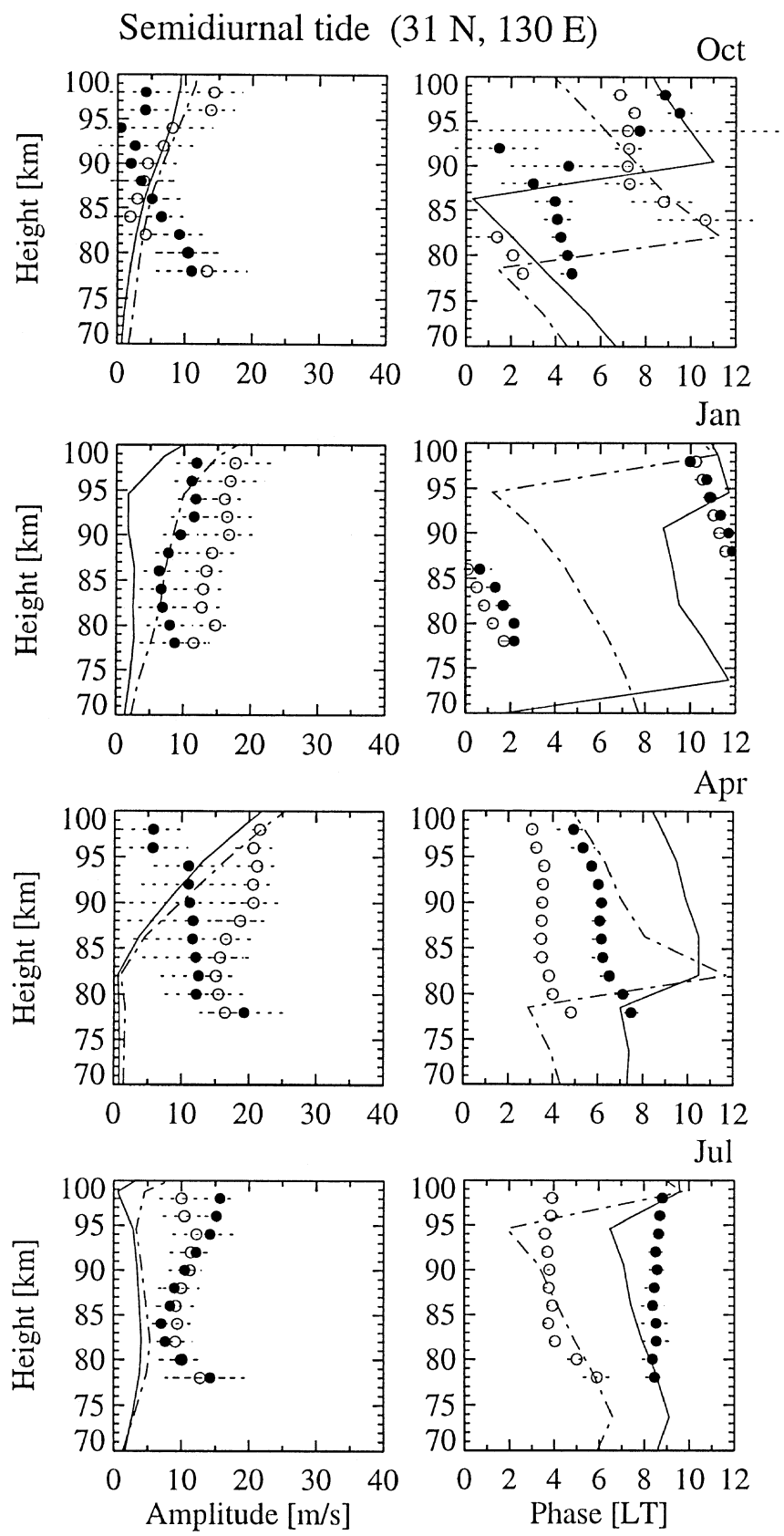

Fig. 7. Same as Fig. 5 but for the semidiurnal tide at Yamagawa $\left(31^{\circ} \mathrm{N}\right)$

M.E. Hagan shows that the model reasonably describes the observed tides. The observed tidal amplitudes are better simulated by GSWM than the phases. The strong annual phase variation of the diurnal tide at Yamagawa and Wakkanai is not predicted by GSWM. Contrary to GSWM, the observed phase profiles of the diurnal tide at Yamagawa indicate longer vertical wavelengths.

Around March equinox the semidiurnal tide at Yamagawa is in antiphase with the observed tide at Wakkanai. This could be due to the excitation of tidal modes of high meridional indices by mode coupling in the mesosphere. These modes should have a node in their horizontal velocity expansion functions between $31^{\circ}$ and $45^{\circ} \mathrm{N}$ (latitudes of Yamagawa and Wakkanai).
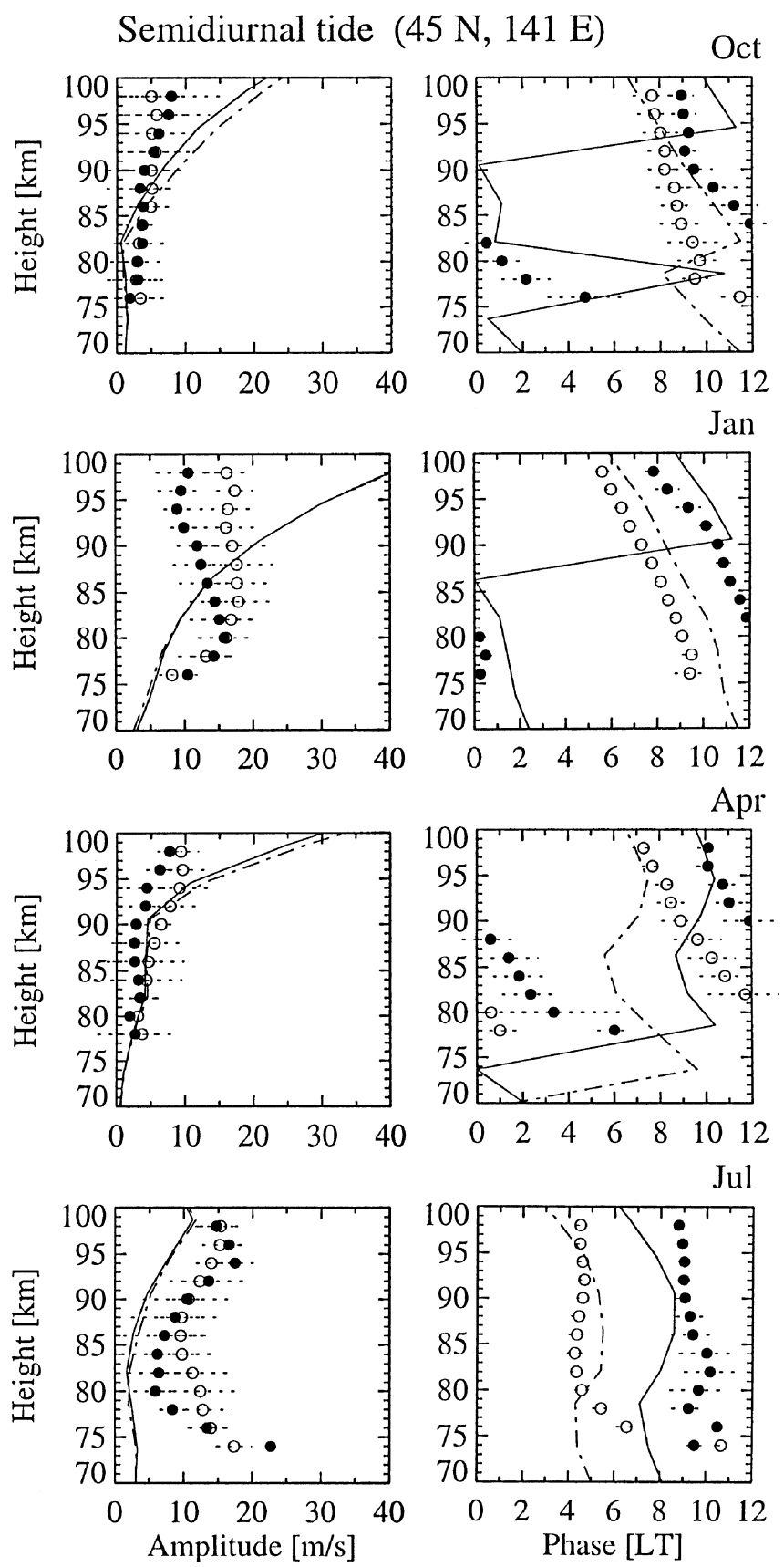

Fig. 8. Same as Fig. 5 but for the semidiurnal tide at Wakkanai $\left(45^{\circ} \mathrm{N}\right)$

The differences between the GSWM results and the observations can be due to interannual variations of the tides, tidally modulated gravity wave flux, instrumental factors, and to the geographic position of Japan, in particular to the prevailing wind field in the mesosphere over Japan. A comparison between the observed mean wind over Japan and the corresponding wind field of the HWM93 model (Hedin et al., 1996) showed significant differences for the meridional wind component (Hocke and Igarashi, 1998). Continuous wind observations by the Japanese MF radars in the next few years will contribute to our knowledge on the average seasonal behaviour of mean winds and tides. 
Acknowledgements. The authors thank M. Nagayama, Y. Makita and I. Nishimuta for operating the MF radars of the Communications Research Laboratory (Ministry of Posts and Telecommunications Japan). We are grateful to M.E. Hagan for providing her GSWM model data on the CEDAR Data Base in Boulder/ Colorado. We thank V. Yudin and the reviewers for improvements and comments. The science and technology agency of Japan is thanked for a research fellowship.

Topical Editor F. Vial thanks W. Singer and another referee for their help in evaluating this paper.

\section{References}

Briggs, B. H., The analysis of spaced sensor records by correlation techniques. MAP Handbook, 13, 166-184, 1984.

Burrage, M. D., Skinner, W. R., Gell, D., Hays, P., Marshall, A., Ortland, D., Manson, A., Franke, S., Fritts, D., Hoffmann, P., McLandress, C., Niciejewski, R., Schmidlin, F., Shepherd, G., Singer, W., and Tsuda, T., Validation of mesosphere and lower thermosphere winds from the high-resolution Doppler imager on UARS, J. Geophys. Res., 101, 10365-10392, 1996.

Chapman, S., and Lindzen, R. S., Atmospheric Tides, D. Reidel, Hingham, Mass., 1970.

Forbes, J. M., Atmospheric tides 2. The solar and lunar semidiurnal components, J. Geophys. Res., 87, 5241-5252, 1982.

Forbes, J. M., Tidal and planetary waves, in The upper mesosphere and lower thermosphere: a review of experiment and theory eds. R. M. Johnson, T. L. Killeen, AGU Geophysical Monograph 87, Washington, 67-87, 1995.

Forbes, J. M., and Hagan, M. E., Diurnal propagating tide in the presence of mean winds and dissipation: a numerical investigation, Planet Space Sci., 36, 579-590, 1988.

Hagan, M. E., Forbes, J. M., and Vial, F., On modeling migrating solar tides, Geophys. Res. Lett., 22, 893-896, 1995.

Harris, T.J., A long-term study of the quasi-two-day wave in the middle atmosphere, J. Atmos. Terr. Phys., 56, 569-579, 1994.

Hedin, A. E., Fleming, E. L., Manson, A. H., Schmidlin, F. J., Avery, S. K., Clark, R. R., Franke, S. J., Fraser, G. J., Tsuda, T., Nakamura, T., Vial, F., and Vincent, R. A., Empirical wind model for the upper, middle and lower atmosphere, J. Atmos. Solar-Terr. Phys., 58, 1421-1447, 1996.

Hocke, K., and Igarashi, K., Mean winds in the mesopause region observed by MF radars at 31 and 45N, J. Atmos. Solar-Terr. Phys., 60, 1081-1087, 1998.

Igarashi, K., Nishimuta, I., Murayama, Y., Tsuda, T., Nakamura, T., and Tsutsumi, M., Comparison of wind measurements between Yamagawa MF radar and the MU radar, Geophys. Res. Lett., 23, 3341-3344, 1996.

Jacobi, C., Schminder, R., and Kuerschner, D., The quasi-two-day wave as seen from D1 LF wind measurements over Central Europe at Collm, J. Atmos. Solar-Terr. Phys., 59, 1277-1286, 1997.

Press, W. H., Teukolsky, S. A., Vetterling, W. T., and Flannery, B. P., Numerical Recipes in Fortran, Cambridge University Press, Cambridge, UK, pp. 670-673, 1992.

Schminder, R., Kuerschner, D., Singer, W., Hoffmann, P., Keuer, D., and Bremer, J., Representative height-time cross-sections of the upper atmosphere wind field over Central Europe 19901996, J. Atmos. Solar-Terr. Phys., 59, 2177-2184, 1997.

Thayaparan, T., Hocking, W. K., and MacDougall, J., Middle atmospheric winds and tides over London, Canada (43N, 81W) during 1992-1993, Radio Sci., 30, 1293-1309, 1995.

Tsuda, T., Aso, T., and Kato, S., Seasonal variations of solar atmospheric tides at meteor heights, J. Geomagn. Geoelectr., 35, 65-86, 1983.

Tsuda, T., Kato, S., Manson, A. H., and Meek, C. E., Characteristics of semidiurnal tides observed by the Kyoto meteor radar and Saskatoon medium-frequency radar, J. Geophys. Res., 93, 7027-7036, 1988.

Vial, F., Numerical simulations of atmospheric tides for solstice conditions, J. Geophys. Res., 91, 8955-8969, 1986.

Vial, F., and Forbes, J. M., Recent progress in tidal modelling, $J$. Atmos. Solar-Terr. Phys., 51, 663-671, 1989.

Vincent, R. A., Tsuda, T., and Kato, S., A comparative study of mesospheric solar tides observed at Adelaide and Kyoto, $J$. Geophys. Res., 93, 699-708, 1988.

Vincent, R. A., Kovalam, S., Fritts, D. C., and Isler, J. R., Longterm MF radar observations of solar tides in the low-latitude mesosphere: Interannual variability and comparisons with the GSWM, J. Geophys. Res., 103, 8667-8683, 1998. 